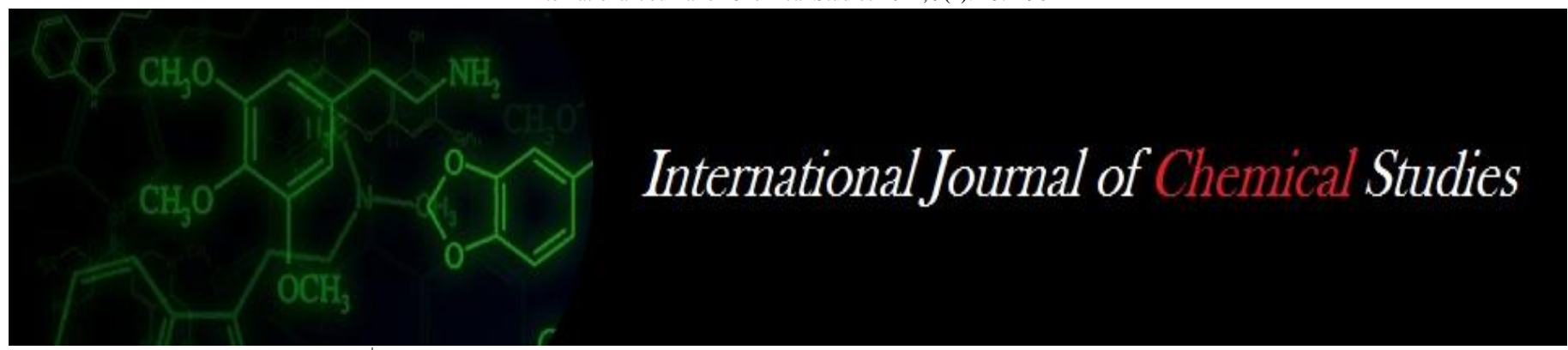

P-ISSN: 2349-8528

E-ISSN: 2321-4902

www.chemijournal.com

IJCS 2021; 9(1): 487-490

(C) 2021 IJCS

Received: 02-11-2020

Accepted: 12-12-2020

\section{Zorinawmi Khiangte}

School of Agriculture,

Department of Agronomy,

Lovely Professional University,

Phagwara, Punjab, India

Anaytullah Siddique

School of Agriculture,

Department of Agronomy,

Lovely Professional University,

Phagwara, Punjab, India

\section{Pulse crops: Steps towards the sustainability in agriculture}

\section{Zorinawmi Khiangte and Anaytullah Siddique}

DOI: https://doi.org/10.22271/chemi.2021.v9.i1g.11278

\begin{abstract}
The strong links between agriculture and the global economy, human civilization and biodiversity make it one of the world's most important environmental frontiers. The demand of food goods is increasing steadily as the population of the world rises. Agricultural activities can conserve and rehabilitate essential environments, protect water sheds, and increase soil and water quality when handle it in a sustainable manner. Hence, there is an increasingly urgent need for sustainable management of resources. However, unsustainable practices make difficult implications for human being and the ecosystem. The use of legumes in sustainable agriculture is one of the most powerful ways to conserve the soil property as it fixes atmospheric nitrogen in the soil through root nodules. The nitrogen-fixing properties of legume crops have a beneficial influence on the ecosystem by increasing soil fertility and reducing the use of inorganic fertilizer requirements. The incorporation of legumes in crop rotations also helps pests and diseases to be mitigated in subsequent crops, helping to minimize farmers' costs and protect the environment.
\end{abstract}

Keywords: Legume crop, nitrogen fixation, sustainable agriculture, soil fertility

\section{Introduction}

Sustainable agriculture is a type of agriculture that focuses primarily on the long-term cultivation of crops, with least environmental effects. It also refers to the conservation and expansion of crop growing conditions. In today's agricultural scenario, food pollution of hazardous chemicals linked to fertilizers, herbicides and pesticides is a major concern. Hence, the global community has also been sensitive to the protection of the environment and food quality over the past two decades. The use of chemical fertilizers is becoming more troublesome as the natural nutrients present in the soil will ultimately move towards complete depletion. The beneficial role of legumes in cropping systems, can be increase by increasing biological nitrogen fixation, lowering energy costs, enhancing soil physical conditions and biodiversity, as more needed at present agricultural scenario (Curty et al., 2014; Peix et al., 2014) ${ }^{[9]}$. Legumes crops fix freely available atmospheric nitrogen into the soil through their root nodules as it has a beneficial effect on the ecosystem by improve soil fertility and decrease inorganic fertilizer requirements. The nitrogen-fixing property of legumes may play a complementary or substitute function as sources of organic fertilizer. Nitrogen is one of the key nutrients needed for proper crop development. Legumes have certain characteristics that are especially ideal for sustainable cropping and conservation agriculture systems, rendering them usable either as crops or as residues of crops. Legume-based cropping systems not only increase yields of grains but also enhance soil fertility by BNF of legumes. Legume residues have a comparatively low $\mathrm{C}$ : $\mathrm{N}$ ratio and are readily decomposed compared to cereals and

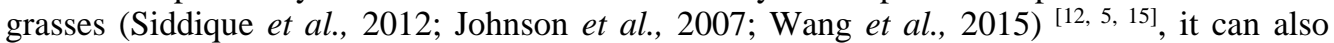
useful as a green manures as well as it also help in minimizing greenhouse gas pollution

\section{Soil fertility management}

Intensive farming and their activities contribute to soil aggregate depletion, which ultimately leads to soil erosion and soil organic matter reduction. While, legumes are considered a good strategy for sustainable land conservation because it prevents soil degradation, increases the water holding capacity and helps preserve the biodiversity of soils. Pulses have been documented to boost the soil aggregates, bulk density, organic carbon, $\mathrm{pH}$, and soil biota
Anaytullah Siddique

School of Agriculture

Department of Agronomy,

Lovely Professional University,

Phagwara, Punjab, India 
population (Mousavi et al., 2019) [7]. Legume-based processes, including soil organic carbon (SOC) and humus material, $\mathrm{N}$ and $\mathrm{P}$ availability, boost many attributes of soil

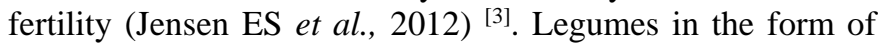
mulch or crop residue serve as soil conditioner because they provide a beneficial effect on microbial populations of the soil by supplying them with a substrate, increasing the deterioration of plant wastes or residues and contributing significant amounts of organic matter to the soil. The cultivation of legumes has a profoundly beneficial impact on soil chemistry as well. The soil $\mathrm{pH}$ decreased due to the production of organic acids and the oxidation of $\mathrm{CO} 2$ in soils. Thus legumes-based crop residue incorporation often serves as a buffer for the soil by maintaining its $\mathrm{pH}$ and also increases the availability of macro or micronutrients. Therefore, practice of intercropping with legumes tends to establish nitrogen-fixing process.

\section{Biological nitrogen fixation (BNF)}

$\mathrm{BNF}$ is a natural process of nitrogen fixation that can be readily accessible and used by plants mediated by microorganisms, such as certain eubacteria, cyanobacteria, antinomies, and a few archaebacteria, commonly called diazotrophs. Plants must enter into a "symbiotic" or mutually beneficial relationship with such bacteria called rhizobia for the fixation process. Not only the legumes themselves, but even any intercropped or subsequent crops will benefit from this, thereby minimizing or eliminating the need to add $\mathrm{N}$ fertilizers. In the next growing season, nearly two thirds of the nitrogen fixed by a legume crop is normally available. $\mathrm{N}$ fixation of grain legumes is about $1.0 \mathrm{~kg} \mathrm{ha}^{-1}$ day $^{-1}$ within a cropping season. While an average amount of $\mathrm{N}$ fixed by gram, pigeon pea, mung bean and lentil are 26-63, 68-200, 50-55 and 35-100 $\mathrm{Kg} \mathrm{ha}^{-1}$.

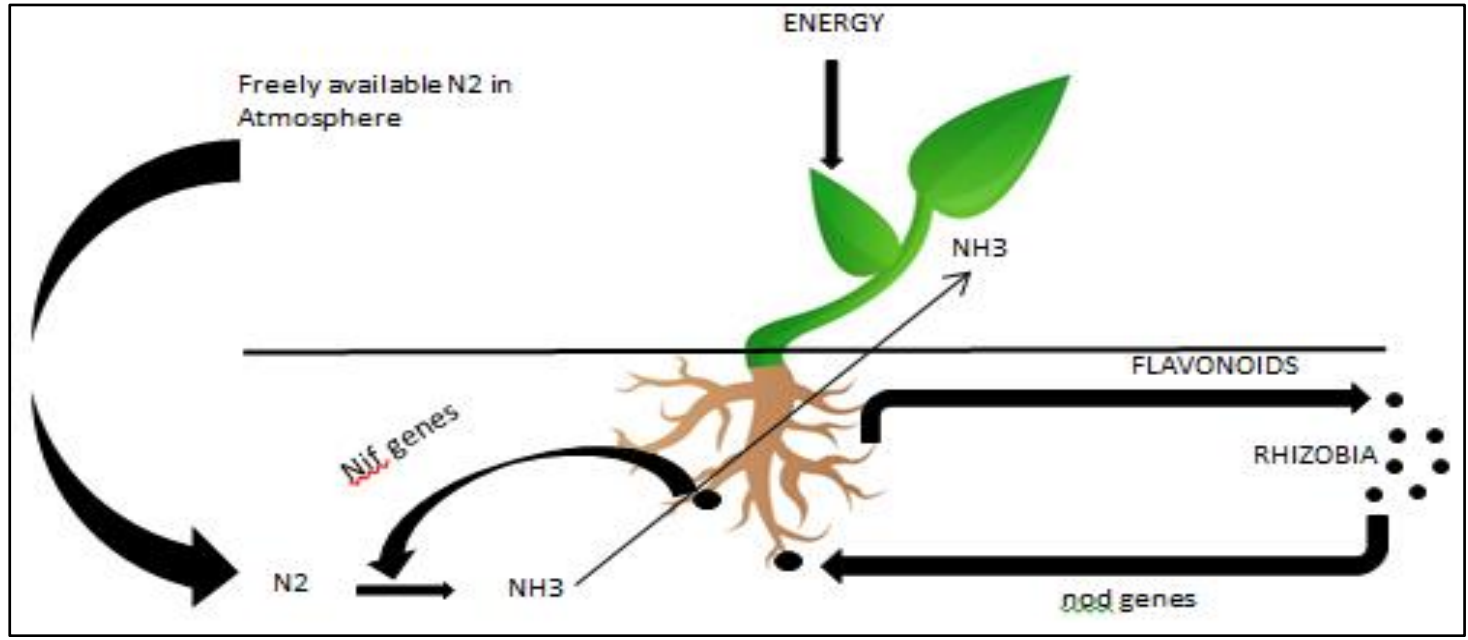

Fig 1: Symbiotic nitrogen fixation in legumes by rhizobia. (Source: Adopted from Kristina Lindstrom and Seyed Abdollah Mousavi, 2019) ${ }^{[7]}$

\section{Impact on the atmosphere}

Of the many considerable advantages that legumes offer to society, their role in contributing to combating climate change has seldom been discussed. Legumes can mitigate greenhouse gas (GHG) emissions such as carbon dioxide (CO2) and nitrous oxide (N2O) compared to mineral $\mathrm{N}$ fertilizationbased agricultural systems, play an important role in soil carbon sequestration and reduce the total fossil energy inputs in the method. The incorporation of legumes into crop rotations helps in minimize fertilizer and energy usage in arable systems, thus lowering emissions of GHGs (Reckling et al., 2016). Jeuffroy et al., (2013) ${ }^{[10,4]}$ compared the amount of GHG emitted by legumes and other crops and it was found that legumes emit about 5-7 times less GHG per unit area in comparison to other crops.

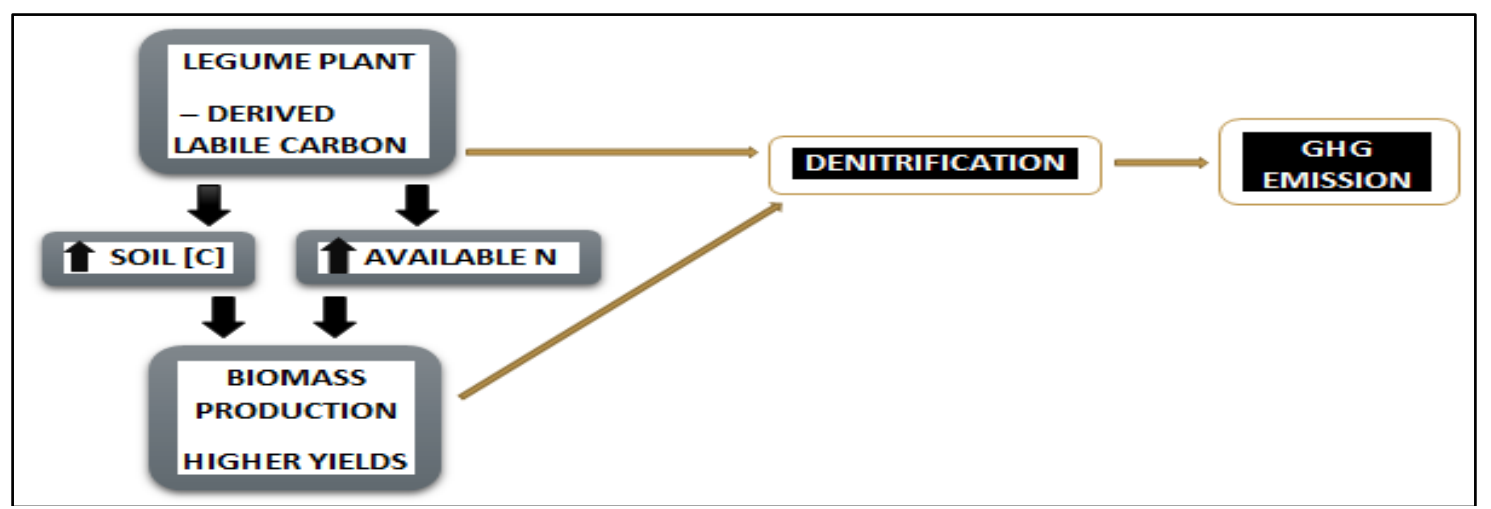

Fig 2: Effect of legumes on soil and greenhouse gas emission (Source: Adopted from Cornelia Rumpel et al., 2017) ${ }^{[1]}$

\section{Legume in green manure}

Legumes are excellent green manure crops, as their decomposed plant matter after harvest can enhance soil water retention, minimize soil erosion and increase SOM, and thereby improve soil assets. Green manure can be grouped into two types based on the position of the manure, i.e. onsite and offsite. In the case of onsite green manure, legumes are planted and applied to the soil on the same field, while in the 
case of offsite green manure; the waste of legumes is gathered at the closest spot and first applied to the soil, so the next crop is planted. In addition, legumes have a broad variety of properties against abiotic and biological stress, such as biological nitrogen fixation, quick period, flexibility in the climate, swift, quick off-farm development, etc. Better control of agricultural sustainability is accomplished by the incorporation of legumes to organic cultivation (Sofi et al., 2018) ${ }^{[14]}$.

\section{Yield of the next harvest in cropping system}

Intercropping is carried out to accomplish multiple ecological objectives, such as fostering interactions between animals, enabling natural regulating mechanisms, increasing biodiversity and reducing the vulnerability of farmers against climate aberration. Intercropping with legumes in particular have high tendency to increase soil $\mathrm{N}$. However, this soil $\mathrm{N}$ may not be available during the current growing season, but will benefit the next crop by improving soil fertility. Any of the surplus fixed nitrogen is entirely used by the second relay crop or will continue to minimize the next crop's nitrogen demand. The growing of Mucuna pruriens and Crotalaria juncea before the cultivation of maize crop has resulted in higher yields of the maize crop upto 4-7 $\mathrm{mg} \mathrm{ha}^{-1}$ and this is without the application of additional $\mathrm{N}$ fertilizer in the next harvest (Lopez and Mundt, 2000) ${ }^{[8]}$. Crop rotation has a major role to play in sustainable agriculture. Accessible data shows that, in the case of intercropping of sorghum and red gramme at a ratio of 2:1 row, the yield was 70 per cent higher than that of the two crops. Further gain was that the nitrogen fixed by the red gramme could be utilized by the sorghum crop. In rice-wheat rotation, short duration mungbean growth in summer can lead to a nitrogen economy of up to $40-60 \mathrm{~kg}$ $\mathrm{N}$ ha ${ }^{-1}$ in succeeding rice crops.

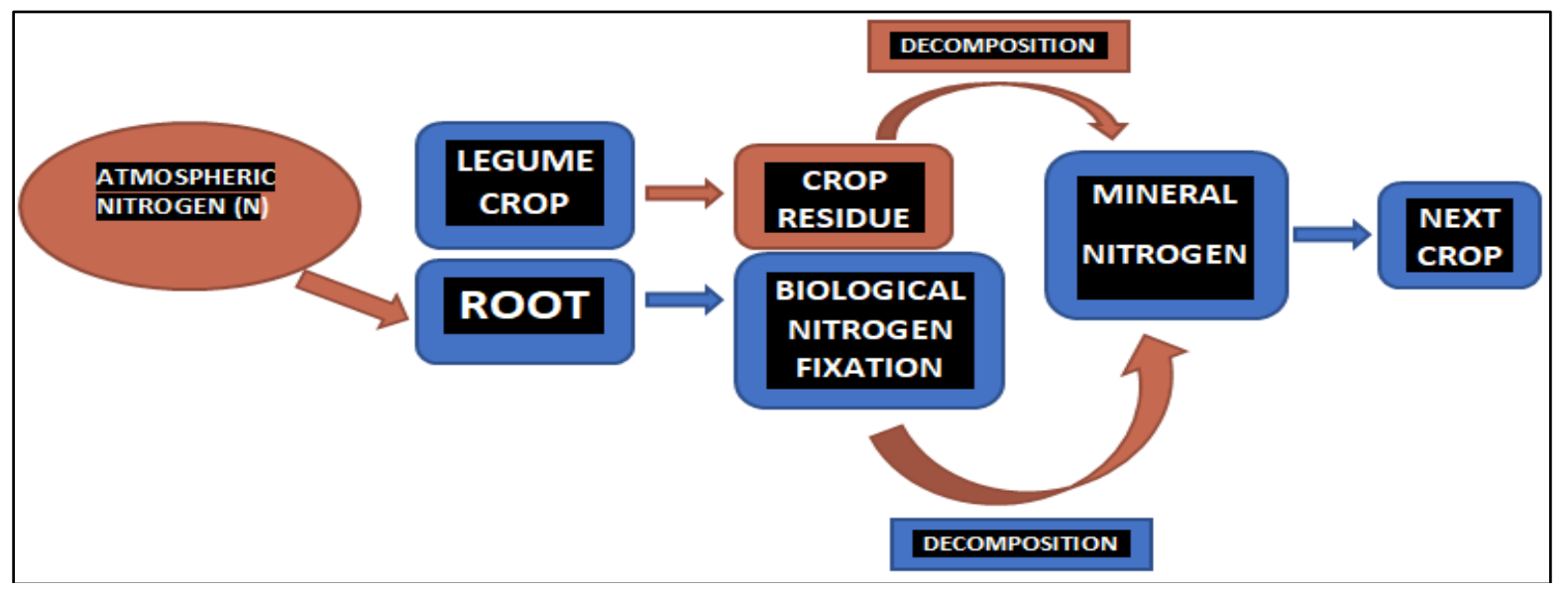

Fig 3: BNF in legumes enhance soil fertility (Source: Julie Grossman, 2019) ${ }^{[6]}$

\section{Conclusion}

In order to maintain sustainability in agricultural systems, the inclusion of legume crops in various farming practices proves to be beneficial in terms of many aspects. These include the maintenances and enhancement in the soil quality which is of great importance in the field of agriculture itself. The possibility of replacing the use of synthetic chemicals, particularly the ones containing nitrogen can be substituted by the incorporation of legume crops in farming systems. As we all know that nitrogen is one of the key nutrients that are essential for the proper growth of crops.

\section{References}

1. Rumpel C, Massad RS, Carozzi M, Chabbi A, Klump K, Leroux $\mathrm{X}$ et al. Is it possible to mitigate greenhouse gas emissions from agricultural soil by introduction of temporary grassland into cropping cycles. Global Symposium on Soil Organic Carbon; Rome, Italy 2017. hal-02734597.

2. Courty PE, Smith P, Koegel S, Redecker D, Wipf D. Inorganic Nitrogen uptake and transport in beneficial plant root-microbe interactions. Critical Reviews in Plant Sciences 2014;34:1-3. Doi: 10.1080/07352689.2014.89 7897.

3. Jensen ES, Peoples MB, Boddey RM, Gresshoff PM, Hauggaard-Nielsen H, Alves BJ et al. Legumes for mitigation of climate change and the provision of feedstock for biofuels and bio refineries: A review. Agron Sustain Dev 2012;32:329-64.
4. Jeuffroy MH, Baranger E, Carrouée B, Chezelles ED, Gosme M, Hénault C. Nitrous oxide emissions from crop rotations including wheat, oilseed rape and dry peas. Biogeosciences 2013;10:1787-97.

5. Johnson JMF, Barbour NW, Weyers SL. Chemical composition of crop biomass impacts its decomposition. Soil Sci. Soc. Am. J 2007;71:155-162. Doi: 10.2136/sssaj2005.0419.

6. Grossman J. Legume inoculation for organic farming systems. e Organic 2019. https://eorganic.org/node/4439.

7. Lindstrom K, Mousavi SA. Effectiveness of nitrogen fixation in rhizobia. Microbial Biotechnology 2019;13(5):1314-133.

8. Lopez CG, Mundt CC. Using mixing ability analysis from two-way cultivar mixtures to predict the performance of cultivars in complex mixtures. Field Crops Research 2000;68(2):121-132.

9. Peix A, Ramírez-Bahena MH, Velázquez E, Bedmar EJ. Bacterial associations with legumes. Critical Reviews in Plant Sciences 2014;34(1-3):17-42.

10. Reckling M, Hecker JM, Bergkvist G, Watson CA, Zander P, Schläfke N. A cropping system assessment framework-evaluating effects of introducing legumes into crop rotations. Eur J Agron 2016;76:186-97.

11. Rubiales D, Mikic A. Legumes in sustainable agriculture. Critical Reviews in Plant Sciences 2015;34(1-3):2-3.

12. Siddique KHM, Johansen C, Turner NC, Jeuffroy MH, Hashem A, Sakar D. Innovations in agronomy for food legumes. A review. Agron. Sustain. Dev 2012;32:45-64. Doi: 10.1007/s13593-011-0021-5. 
13. Singh A, Singh HC. Organic Grain Legumes in India: Potential Production Strategies, Perspective, and Relevance. Intech Open 2020. DOI: 10.5772/intechopen.93077.

14. Sofi PA, Baba ZA, Hamid B, Meena RS. Harnessing soil Rhizobacteria for improving drought resilience in legumes. Legumes for Soil Health and Sustainable Management. Springer 2018. DOI: 10.1007/978-981-130253-4_8.

15. Wang J, Chen X, Zhang YJ, Gao HJ. Characteristic of wheat straw decomposition under aerobic and anaerobic condition in soil. J. China Agric. Univ 2015;3:023. 